\title{
The ultimate paper
}

$\mathrm{T}$ he other night I dreamed a dream Whose message came through strong That every paper up to now was incorrect and wrong

A Freudian dash up to my desk Before the dream could turn to vapour Took pen and paper and with the muse Sat down and wrote the paper

'Twas a paper to end all papers, and To set all medicine straight For there's nothing right ever written prior To nineteen eighty-eight

To every editor on the planet A copy of the opus was sent It caused the wildest consternation From Calgary to Tashkent

To every journal on the globe In every script, in every tongue 'Twas typed on floppies, set in morse And spoken or shouted or sung In every paper previously sent, I showed In each and every medical journal Enough errors, faults and misprints To please the fiend infernal

Physicians in universities or colleges And others with jobs to cherish On topics mundane or exotic Have perforce to publish or perish

I showed that in all this writing In which so much time was sunk Was a simple turning, and churning ie, that is, all junk

The paper was panned by reviewers "Too much data" they wrote "The title is wrong", "Not new", "Too old" "Confused", "mixed up", to quote
But editors lauded the paper

And all deplored the reviewers

The editors thought it was wondrous

And all ignored the reviewers

Tho' editors may argue or bicker

Their feelings are not what they seem

To publish this master of papers

Was every editor's dream

Vying to see who would be first The editor's to my consternation Fought tooth and nail for the honour Of earliest publication

'Twas the only paper abstracted in Yearbooks

And purchasers responded in glee In deference to all the pages lost There was a lowering of the cost The first in history

The Yearbooks abstracted only my paper

For the year, which caused a din

All references were started from that date

And the book was one page thin

The date that the paper appeared

Was labelled year one, AP*

And everything prior was straightaway sunk

By garbage scows at sea

All honours followed the paper, and

My head swelled to marvellous size

When all savants in Sweden

Awarded the Nobel Prize

But when I went upon that day,

The Nobel Prize to take up

I found all swirling in a fog

And it was time to wake up

* Anno paperensis. The year of the paper. $(L)$

F.I. Jackson, $M B$

Senior Radiologist, Cross Cancer Institute Edmonton, Alberta 


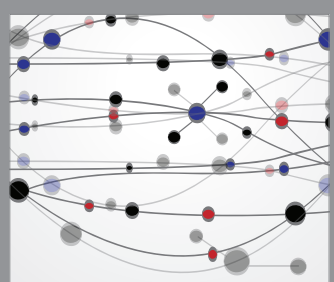

The Scientific World Journal
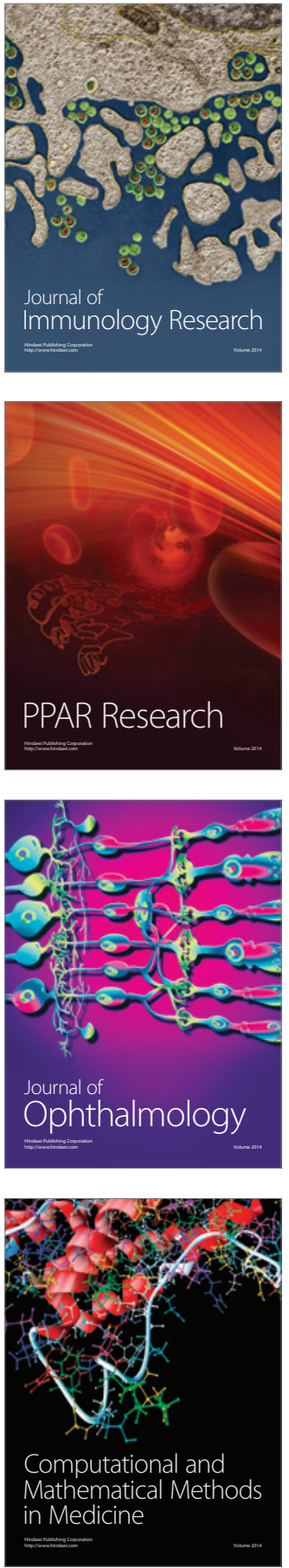

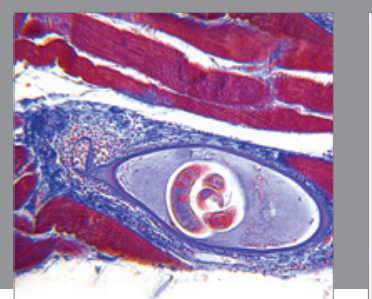

Gastroenterology Research and Practice

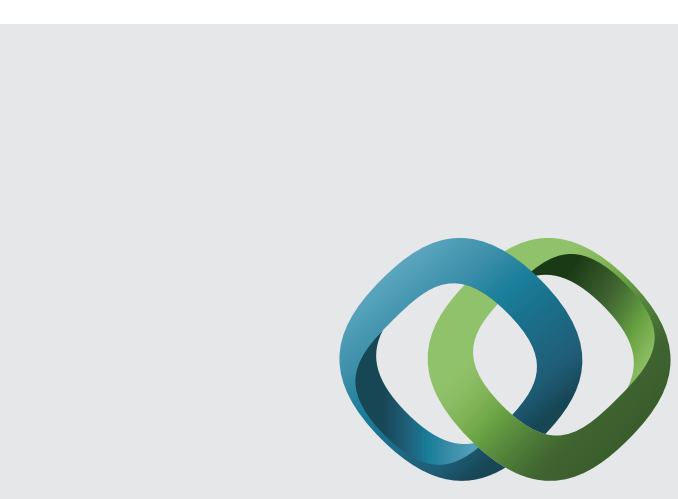

\section{Hindawi}

Submit your manuscripts at

http://www.hindawi.com
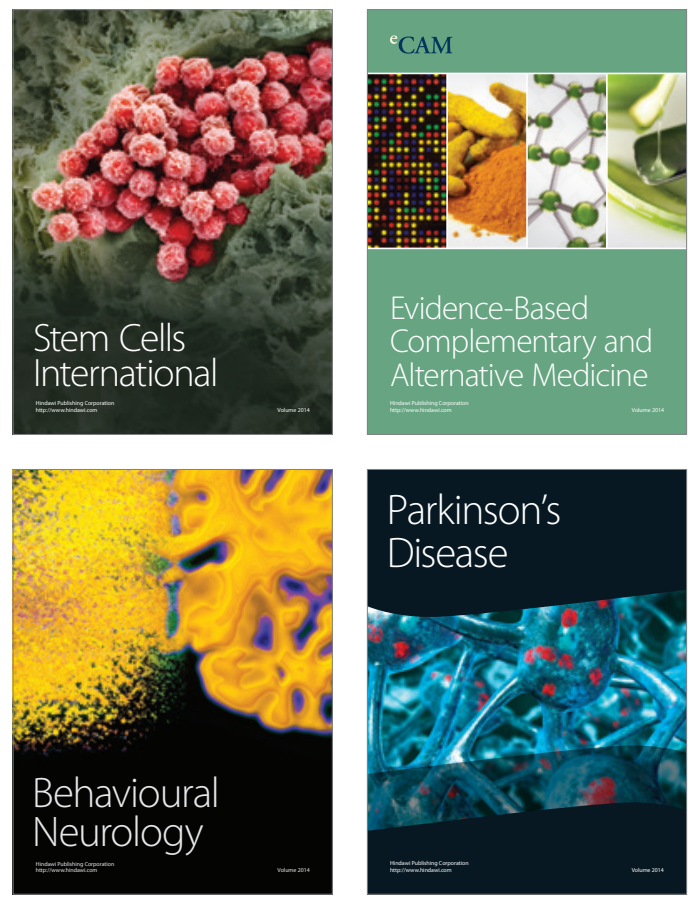
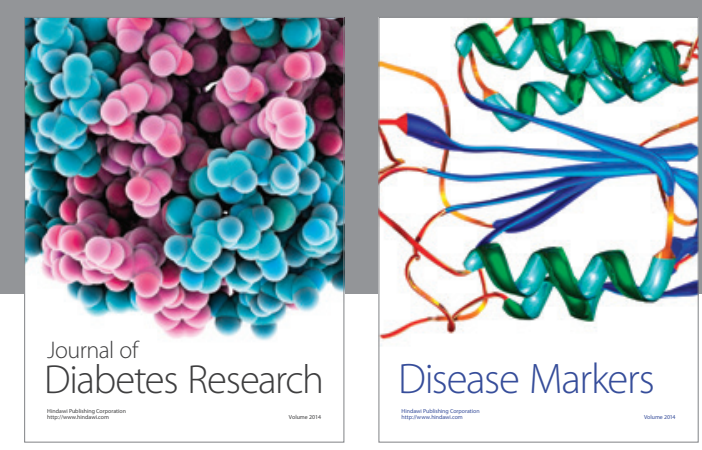

Disease Markers
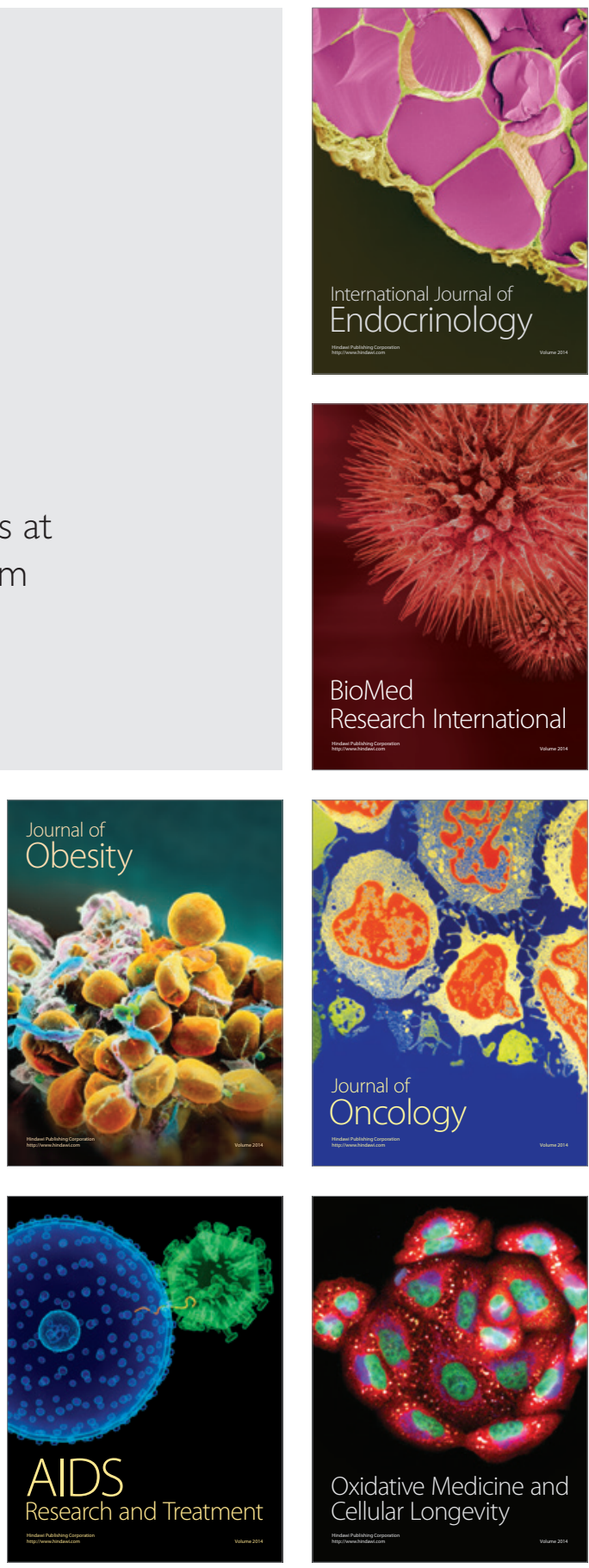